\section{O corpo transparente: visualização médica e cultura popular no século XX}

\section{The transparent body: medical imaging and popular culture in the twentieth century}

Francisco Ortega

Filósofo, professor adjunto do Instituto de Medicina Social da Uerj

Rua São Francisco Xavier, 524, $7^{\circ}$ andar, Bloco B 20599-900 Rio de Janeiro - RJ - Brasil fjortega@uol.com.br fjortega@superig.com.br
ORTEGA, F.: O corpo transparente: visualização médica e cultura popular no século XX.

História, Ciências, Saúde - Manguinhos, v. 13 (suplemento), p. 89-107, outubro 2006.

Este artigo analisa o sucesso das novas tecnologias de visualização médica, as quais têm dado relevância ao interior do corpo humano que não encontra precedentes nas nossas sociedades. Essas tecnologias extrapolam o campo estritamente biomédico e se introduzem no campo cultural e jurídico. O artigo traça uma genealogia das diferentes tecnologias médicas de visualização do corpo humano e do cérebro no século XX, desde os raios $X$ até as imagens mais sofisticadas de CT, IRM e PET. Pretende-se explorar as modificações na corporeidade resultantes da crescente visualização, assim como a recepção dessas tecnologias em tribunais e na cultura popular, especialmente na literatura, no cinema e nas revistas de divulgação.

PALAVRAS-CHAVE: corporeidade; visualização médica; cultura popular; neurociências.

ORTEGA, F.: The transparent body: medical imaging and popular culture in the twentieth century.

História, Ciências, Saúde-Manguinhos, v. 13 (supplement), p. 89-107, October 2006.

In today's societies, successful new medical imaging technologies have focused unprecedented attention on the inside of the human body. These techniques have jumped the walls of the biomedical field per se, penetrating the fields of culture and law. The article traces a genealogy of twentieth-century medical techniques used to visualize the human body and brain, from Xrays to the more sophisticated CTs, MRIs, and $P E T$ scans. It explores the changes that these ever more numerous visualization techniques have occasioned in our corporality and examines how these technologies have been received in the courtroom and in popular culture, especially in literature, movies, and magazines.

KEYWORDS: corporality; medical imaging; popular culture; neurosciences. 
1 O romance é publicado em alemão em 1924. A história se encerra com a eclosão da Primeira Guerra Mundial, em 1914, e a incorporação do protagonista à contenda. Como Hans Castorp havia permanecido sete anos no sanatório Berghof em Davos, e o episódio dos raios $\mathrm{X}$ acontece no início de sua estada, este deve ter ocorrido em 1907.
2 Entre as exceções se encontra o interessante artigo de Danius (2000).

\section{Na Montanha Mágica}

“ tulo que Thomas Mann dedica ao encontro de Hans Castorp com os raios $\mathrm{X}$ no seu monumental romance, A montanha mágica (Der Zauberberg). Esse texto captura de modo absolutamente singular a atmosfera de estranheza e o impacto subjetivo causado pelas novas imagens nos indivíduos que tomaram contato com elas na virada para o século XX. A primeira experiência do protagonista com a nova tecnologia acontece em 1907, ${ }^{1}$ num momento em que os raios $X$ eram ainda uma relativa novidade. Uma das primeiras questões que surgem no referido capítulo diz respeito à relação da visão com a legibilidade, que vai colocar em xeque o pretenso estatuto de neutralidade e objetividade das imagens. Defrontando-se pela primeira vez com as imagens de raios X, Hans Castorp não consegue 'ver' nada. É só depois de o médico do sanatório, o conselheiro Behrens, mostrar-lhe as diferentes partes anatômicas, que Castorp exclama: "Sim, sim, eu vejo ... Deus meu, eu vejo!" (Mann, 2000, p. 299). O episódio enfatiza a necessidade de um olhar decodificador que ajude a 'ver' o que está sendo apresentado, uma linguagem capaz de nomear o que está sendo olhado, que acompanha as tecnologias de imageamento corporal. O episódio nos descreve, além disso, a sensação de estranheza, de transgressão e fantasmagoria que envolve o primeiro encontro com o interior do corpo, expresso na singular mistura de sentimentos que inundam o peito do protagonista, numa bela análise fenomenológica. $\mathrm{O}$ "angustiante prazer da indiscrição" se confunde com sentimentos de "comoção e piedade" (ibidem, p. 299). E por isso, quando Castorp contempla a própria mão no aparelho de raios $X$, a certeza de sua própria morte lhe é confirmada pela visualização do seu esqueleto. Nas elegantes palavras de Thomas Mann,

Hans Castorp viu o que devia ter esperado, mas que, em realidade, não cabe ver ao homem, e que jamais teria crido poder ver: lançou um olhar para dentro do seu próprio túmulo. Viu, antecipado pela força dos raios, o futuro trabalho da decomposição; viu a carne em que vivia, solubilizada, aniquilada, reduzida a uma névoa inconsistente, no meio da qual se destacava o esqueleto minuciosamente plasmado da sua mão direita ... Com os olhos daquela parenta da família Tienappel, contemplou uma parte familiar de seu corpo, estudou-a com olhos videntes e penetrantes, e pela primeira vez pensou que estava destinado a morrer. (Ibidem, p. 300)

Os analistas da obra de Thomas Mann não têm enfatizado a centralidade desse episódio no romance, ${ }^{2}$ mas a visualização do próprio esqueleto, a visão antecipada de sua morte, tem um signi- 
3 É interessante ressaltar que as imagens produzidas pelos PET-scanners e pelos aparelhos de ressonância magnética não mostram o esqueleto, o qual só é visualizado na tomografia computadorizada. Como as IRM e as imagens produzidas pelos PET-scanners são as mais difundidas na cultura popular e no imaginário coletivo, perde-se gradualmente a associação com a morte, dada pela visualização do próprio esqueleto. ficado existencial e ontológico na vida do engenheiro Hans Castorp. A partir desse momento deixa para trás sua existência burguesa e dá início aos estudos científicos e filosóficos, transformando-se em um intelectual e cortando os laços com o mundo que se estende além do sanatório. Ele é invadido por uma vontade de saber sobre o corpo que abarca desde a anatomofisiologia até a metafísica, num processo que lembra o percurso descrito nos romances de formação (Bildungsroman) alemães, cujo modelo clássico é Os anos de aprendizagem de Wilhelm Meister de Goethe. Para Castorp, a autoformação intelectual está ligada à descoberta e ao conhecimento do corpo, o que poderíamos denominar de somatização do ideal clássico da Bildung, de Bildung fisiológica. O conhecimento do interior do corpo representa uma metáfora eficaz do conhecimento de si.

\section{Raios X na cultura popular}

Thomas Mann nos descreve uma vivência comum nos indivíduos que tomaram contato com a tecnologia no início do século passado. Declarações como as de um paciente em Chicago, que, depois de ver a imagem de raios $X$ do próprio corpo, exclamou: "sinto-me mais instruído sobre mim mesmo. Tracei uma imagem mental do que está lá dentro" (citado em Kevles, 1998, p. 267), lembram a experiência do protagonista do romance de Thomas Mann no sanatório Berghof, em Davos. Um século depois da descoberta de Roentgen, a visão do interior do corpo continua ligada ao conhecimento de si, como se depreende da seguinte observação de uma artista em 1993: "Meus ossos foram escaneados no ano passado e fiquei totalmente assombrada do conhecimento acerca de mim mesma que atingi ao ver meu esqueleto aparecer na tela" (em Kevles, 1998 , p. 267). Na atualidade, as imagens do nosso interior popularizaram-se com os novos aparelhos de visualização. Mesmo quem nunca tenha sido submetido a um exame com os modernos scanners tem se encantado com as novas imagens que freqüentemente aparecem em programas de televisão, filmes e revistas de divulgação. Numa cultura na qual a intimidade deixou de ser valorizada e protegida, passando a ser exposta nos mais ínfimos detalhes em reality shows, programas de auditório, diários na Internet e outros teatros do eu contemporâneos, a interioridade visceral revelada pelas novas imagens acompanha esse processo de externalização. Apesar de essas imagens serem tão pessoais e 'íntimas' por pressagiar de maneira tão eficaz nossa condição mortal, ${ }^{3}$ estamos nos acostumando à sua difusão e reprodutibilidade.

A situação era, no entanto, diferente um século atrás. Muitas pessoas sentiram-se ultrajadas com a idéia de as imagens do interior de seus corpos tornarem-se públicas, mesmo que anonimamente. Fazia parte do senso comum considerar que as imagens eram 
${ }^{4}$ O que constituía um problema no exame físico do paciente feminino era a visão, não o tato. $\mathrm{O}$ médico podia 'tocar' o corpo feminino e até mesmo romper o hímen com o dedo, contanto que não olhasse. Os médicos norteamericanos oitocentistas não examinavam as pacientes com $\mathrm{o}$ recém-criado speculum vaginal por

considerar-se “injustificável do ponto de vista da propriedade e da moral" que um médico olhasse a genitália de uma mulher (citado em Kevles, 1998, p. 119). privadas e íntimas, e portanto deviam ser zelosamente protegidas. Vale como exemplo o caso das radiografias que eram tiradas rotineiramente nos anos 40 e 50 dos estudantes das universidades de elite americanas, a Ive League. Essas imagens, que se acreditava tivessem sido destruídas, apareceram nos arquivos de alguns antropólogos, os quais as tinham utilizado sem permissão dos sujeitos envolvidos. Os indivíduos cujas imagens foram usadas exigiram que estas fossem imediatamente reduzidas a cinzas (Kevles, 1998).

Roentgen fez sua descoberta em novembro de 1895, em plena era vitoriana, época de repressão sexual e vergonha do corpo nu. Numa época em que homens e mulheres tomavam banho de mar cobertos da cabeça aos pés, espelhos capazes de refletir o corpo inteiro eram um luxo para poucos e pacientes femininas permaneciam ocultas atrás de cortinas de veludo, estendendo a mão ao serem examinadas pelo médico ${ }^{4}$ uma tecnologia que parecia revelar os segredos do corpo causava desconforto. Donde a observação do conselheiro Behrens a Hans Castorp: "Parece, Castorp, que o senhor tem medo de nos revelar o seu interior" (Mann, 2000, p. 294). Os raios $X$ são contemporâneos do nascimento da psicanálise, ambos são "fenomenologias do interior" (Lippit, 1996). A possibilidade de anatomizar e visualizar o psiquismo acompanha as novas formas de anatomizar e visualizar o interior do corpo. A ligação com a sexualidade é comum em ambas as fenomenologias da interioridade. Os raios $X$ ameaçavam expor a parte mais secreta do corpo humano, os órgãos genitais. Especialmente os corpos femininos deviam ser zelosamente protegidos por pais e maridos. Uma firma de tecidos de Londres chegou a oferecer calcinhas à prova de raios X (Kevles, 1998), seguramente de chumbo!

$\mathrm{Na}$ sociedade vitoriana da intimidade e da sentimentalidade na qual os raios $\mathrm{X}$ aparecem, o indivíduo protegia com grande esmero a sua interioridade emocional e moral da visibilidade do mundo. Existiam fronteiras claras entre o público e o privado, separando o que o sujeito era na sua vida íntima e privada do modo como ele se apresentava no mundo público, e delimitando os espaços internos e externos do corpo. Nessa cultura de demarcações claras e precisas entre interior e exterior, essência e aparência, visível e invisível, público e privado, as imagens de raios $X$ contribuíram para apagar distinções sociais e morais, e a própria idéia de privacidade e intimidade começou a mudar. No início, alguns indivíduos viam na nova tecnologia uma invasão da privacidade doméstica e da intimidade moral, temendo que os raios $X$ pudessem ver através dos muros de suas casas. Uma nota publicada no Pall Mall Gazette de Londres, em março de 1896 (isto é, apenas quatro meses depois da descoberta de Roentgen), descreve a atmosfera de insegurança e desconforto que os raios $X$ provocavam. A nota é tão elucidativa que merece ser reproduzida em sua totalidade: 
Estamos enojados com os raios Roentgen. Diz-se agora, esperamos que inveridicamente, que Mr. Edison descobriu uma substância - seu nome repulsivo é tungstato de cálcio - que potencializa (o que quer que isto queira dizer) os ditos raios. A conseqüência disso parece ser que se podem ver os ossos das outras pessoas a olho nu, e também ver através de oito polegadas de madeira sólida. Não há necessidade de nos estendermos sobre a revoltante indecência disto. Mas estamos chamando seriamente a atenção do Governo para o fato de que, no momento em que o tungstato de cálcio se tornar de uso geral, haverá necessidade de legislação restritiva do tipo mais severo possível. Olhar através da porta de uma pessoa é um crime tão sério quanto falsificar seu nome, e fazê-lo sem autorização deveria realmente ser punido com uma longa estadia de trabalhos forçados na prisão. Da mesma maneira, olhar os ossos de outra pessoa sem permissão deveria ser encarado como uma forma grave de atentado ao pudor. Mas mesmo a legislação mais severa só poderia, no máximo, controlar as práticas mais revoltantes. Talvez a melhor coisa seria todas as nações civilizadas fazerem um pacto: queimar todos os trabalhos sobre os raios Roentgen, executar todos os descobridores, juntar (isolar) todo o tungstato do mundo, e afundá-lo no meio do Atlântico. Deixem os cetáceos, e não nós, contemplarem os ossos uns dos outros. (Apud Chazan, 2003, p. 212)

Num poema de Emily Culverhouse de 1897, o qual resume as apreensões populares, a autora observa que antes de os "raios impertinentes do doutor Roentgen" terem invadido nossas estruturas "o corpo de um inglês pertencia a ele mesmo", e que a nova tecnologia fixará "nossas mentes de modo uniforme", e "desenhará a imagem gerada por nosso cérebro e revelará a nossa percepção mais íntima" (citado em Kevles, 1998, p. 28). Diante dessa invasão, ninguém estaria seguro.

Apesar da desconfiança inicial, o mundo rapidamente acolhe a mudança radical na percepção introduzida pelas imagens de raios $X$. No campo estritamente médico, o ambiente era favorável para receber a nova tecnologia. Desde a segunda metade do século XVII apareceram os primeiros aparelhos para visualizar o interior dos órgãos (Segal, 1979). Mas é no século XIX que surgiu uma série de instrumentos de visualização, como é o caso do oftalmoscópio em 1850 e o laringoscópio em 1857. A eles se seguiram outras ferramentas para visualizar a vesícula, o estômago, o reto e a vagina, auxiliadas pela invenção da lâmpada em 1881 e pela fotografia (Kemp, 1998; Reiser, 1990). Todos esses instrumentos colocavam uma ênfase especial na visão, em continuidade com a tradição anatômica, produzindo concepções fragmentadas e atomizadas do corpo humano e uma desconfiança no uso diagnóstico dos outros sentidos, especialmente do ouvido e do tato. Nesse clima, a aparição dos raios $X$ não constituiu uma ruptura epistemológica radical com outros 
5 Basta visitar o site da maior livraria virtual mundial, a Amazon (www.amazon.com), para encontrarmos vários livros como o título de Neurotheology. Numerosos experimentos procuram o ponto de Deus no cérebro e estudam com ajuda de PET-scanners as mudanças neurais de indivíduos submetidos a práticas de meditação. Sobre esse campo fascinante entre a ciência e a espiritualidade, ver o excelente livro de John Horgan (2003). A revista Zygon: Journal of Religion $\mathcal{E}$ Science inclui freqüentemente artigos sobre essa temática. meios de visualização da época, no que diz respeito ao privilégio da visão e à fragmentação e atomização do corpo. A profusão de publicações especializadas - só em 1896, isto é, um ano depois da descoberta, vieram à luz 49 livros e mais de mil artigos científicos sobre o tema (Gugerli, 1999) - revela a enorme atenção despertada pela nova tecnologia.

O interesse pelos raios $X$ não se limita ao âmbito estritamente biomédico, difundindo-se rapidamente no campo sociocultural e jurídico e capturando de forma singular a imaginação popular. Poucas semanas após da descoberta já existiam máquinas de raios X em Chicago e Kansas, onde, por uma moeda, podiam ver-se os ossos da mão. Lojas de departamentos ofereciam exibições com raios X em ambos os lados do Atlântico, como uma maneira de atrair clientes, e muitas pessoas construíram suas próprias máquinas de raios $X$ no porão de suas casas. Várias celebridades européias, como a czarina de Rússia, o imperador Guilherme II da Alemanha, o primeiro-ministro da Inglaterra e a rainha Emilia de Portugal, expunham alegremente braços, mãos e outras partes do corpo ao escrutínio dos novos raios. As imagens de raios $X$ tornaram-se rapidamente objetos de alto valor sentimental. Basta lembrar os pacientes do sanatório de Berghof trocando entre eles suas imagens de raios X, e de Hans Castorp levando consigo o "retrato interior" de sua amada Clawdia Chauchat. Entre os estudiosos mais dedicados dos raios X encontravam-se psicólogos e parapsicólogos, consagrados a explorar a quarta dimensão, auras psíquicas e percepção extra-sensorial. Era comum entre espiritualistas e outros observadores leigos religiosos identificar as imagens de raios $\mathrm{X}$ com imagens da alma (Cartwright, 1997). A associação com a religião e a espiritualidade é uma marca comum das diversas tecnologias do imageamento, especialmente de visualização cerebral, que levou no final do século $X X$ ao surgimento de áreas de investigação como neuroteologia, neuroescatologia e neuroesoterismo, com o objetivo de delimitar no cérebro a zona responsável pela espiritualidade. ${ }^{5}$ No âmbito jurídico, em meio a um grande debate que dizia respeito ao estatuto de objetividade das novas imagens e ao conflito entre evidências verbais e visuais, a primeira imagem de raios $X$ foi usada como evidência em fevereiro de 1896 num tribunal de Montreal, e, por volta de 1900, sucedem-se os casos de apresentação das imagens, principalmente em casos de negligência médica. Especialmente esses casos criavam uma situação embaraçosa por os médicos desempenharem a dupla função de acusado e de expert capaz de julgar as imagens, inacessíveis ao olhar não treinado dos leigos (Gugerli, 1999; Kevles, 1998; Reiser, 1990).

As técnicas de visualização no século $X X$, dos raios $X$ aos sofisticados PET-scanners (tomógrafos por emisão de pósitrons), produziram e ainda produzem um fascínio inusitado sobre a psique 


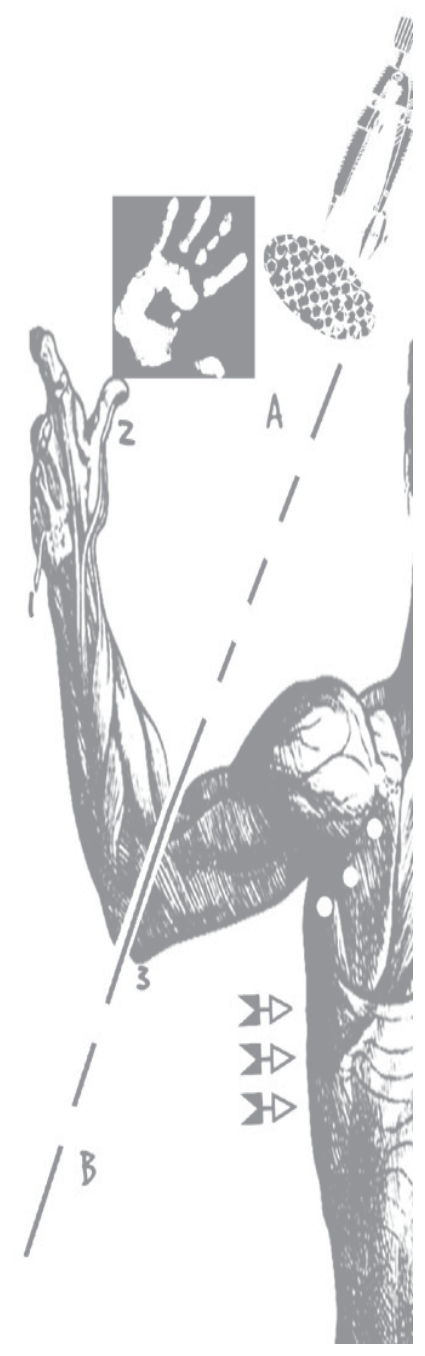

coletiva, ultrapassando rapidamente a esfera biomédica de origem. De modo singular as imagens do interior do corpo transitam entre o conhecimento especializado e a fantasia popular, a pesquisa científica e os processos de divulgação, que incluem a arte e a cultura popular. Os raios X entraram em seguida no terreno da ficção: no romance de H. G. Wells The invisible man, de 1897, o protagonista descobre um raio análogo aos "raios Roentgen", capaz de tornar seu corpo invisível, e no romance de W. S. Harris Life in a thousand worlds, publicado em 1905, os cientistas são capazes de "seguir o curso de um pensamento em um cérebro vivo depois de este ter sido tornado visível por uma luz mais potente que os raios $X^{\prime \prime}$ (citado em Kevles, 1998, p. 118), antecipando os sonhos e anelos das neurociências mais recentes. Após a Primeira Guerra Mundial, a transparência da carne, fornecida pela tecnologia, tornou-se um lugar comum, e encontramos os raios $\mathrm{X}$ ocupando um espaço nas esferas culturais e políticas: desde a análise da liberação feminina, presente no romance de 1923 Black oxen, à investigação de desvio sexual, como mostra um estudo realizado em 1935 em Nova York com um grupo de homens e mulheres homossexuais que se submeteram aos raios $X$ para provar que não eram perigosos. Mas é no terreno da avant-garde artística que as imagens causam um profundo impacto com seu ideal de transparência, que deixa marcas tanto na arquitetura transparente da escola Bauhaus alemã, quanto nas vanguardas soviética e italiana. No Technical manifesto of futurist painting, de 1910, o porta-voz dos futuristas italianos, Umberto Boccioni, inquire: "Quem pode ainda acreditar na opacidade dos corpos ... quando nossa sensibilidade aguçada e multiplicada nos permite perceber as revelações obscuras dos fenômenos mediúnicos? Por que deveríamos continuar criando sem levar em conta nossos poderes perceptivos que podem dar resultados análogos aos dos raios X?" (apud Kevles, 1998, p. 130).

Nos mais diversos contextos culturais e científicos, os raios $X$ promovem uma mudança radical na imagem que os indivíduos tinham de si mesmos e de seus corpos, um novo ideal de transparência que dissolve a opacidade e a densidade do corpo, antecipando a sua virtualização pós-moderna. Não surpreende que na época fizesse sucesso um modelo anatômico de cera chamado de "homem transparente", exibido pela primeira vez no museu de higiene de Dresden e que viajou pelo mundo inteiro, o qual consistia de um esqueleto verdadeiro recheado de falsos órgãos confeccionados a partir de diferentes modelos e protegidos por uma camada fina de celulóide. O modelo tornou-se um ícone poderoso do movimento eugenista alemão, como metáfora da superação da corporeidade associada à impureza (Vogel, 1999). 


\section{Construção de evidências sócio-técnicas}

Como dispositivo eficaz de produção de imagens do interior do corpo humano, os raios $X$ ficaram sem concorrência durante meio século, pelo menos até o final da Segunda Guerra Mundial. A partir dos anos 50 a situação muda de maneira drástica e as inovações se sucedem rapidamente: ultra-sonografia, tomografia computadorizada - TC, tomografia de ressonância magnética - IRM, e Tomografia por Emisão de Pósitrons - PET. A onda de euforia e entusiasmo público desencadeada pela descoberta de Roentgen tampouco é comparável com a recepção obtida pelas novas tecnologias de imageamento entre médicos, pacientes, físicos e químicos. Em 1895, o trabalho de Roentgen sobre os novos raios foi publicado em poucos dias (o que não deixa de ser surpreendente, se pensamos que hoje leva um mínimo de três a seis meses para um paper científico vir à luz), da mesma maneira que o intervalo entre a descoberta dos raios e a produção das primeiras imagens foi também de poucos dias. Em contrapartida, passaram-se três decadas entre a medição da ressonância nuclear magnética por Edward M. Purcell e Felix Bloch em 1946 e a produção da primeira imagem de ressonância magnética do corpo humano (Gugerli, 1999; Kevles, 1998; Dolby \& Alker, 1997). Apesar da demora em comparação com os raios $X$, houve e continua havendo uma onda de euforia pública com as novas tecnologias de imageamento, incentivada em grande medida pelas estratégias de marketing dos produtores de scanners. Como ilustração desse fato, no jornal suiço Neuen Zürcher Zeitung aparece um artigo em 1983 comentando o marketing intenso realizado por determinadas empresas para máquinas que não saíram ainda do papel, quanto menos foram construídas; a demanda das clínicas pelos novos aparelhos, "embora saiba-se bastante pouco das possibilidades reais da técnica diagnóstica correspondente; e a construção de prédios especiais nos hospitais para acolher aparelhos que ainda não estão no mercado" (apud Gugerli, 1999).

Ainda que à primeira vista as novas imagems se apresentassem como continuação automática no processo de colonização do interior do corpo iniciado pelos raios $X$, logo viu-se que a situação colocada pelas novas formas de imageamento era diferente, não podendo inserir-se nos contextos socioculturais e nas convenções e normas visuais existentes. Desse modo iniciou-se, em meados dos anos 80, uma ampla discussão acerca das possibilidades diagnósticas da IRM -Tomografia de Ressonância Magnética. Buscava-se esclarecimento sobre os procedimentos utilizados, a diferenciação em relação a formas de tomografia já existentes e a aplicação da nova tecnologia a toda uma série de disciplinas médicas. O National Institute of Health, dos Estados Unidos, organizou em outubro de 1987 a chamada "Conferência para o desenvolvimento de consenso" 
(Consensus Development Conference), na qual se definia a IRM como a "nova e inovativa técnica que proporciona imagens anatômicas em múltiplos planos e que fornece informação sobre a caraterização tecidual". Foram descritos os procedimentos, a diferença em relação a outro tipo de imagens - especialmente as de raios $X-$, assim como uma relação imensa de objetos passíveis de ser visualizados e uma ampla e ambígua lista de interessados potenciais, com o objetivo de criar um espaço de possibilidade no qual ninguém, em princípio, fosse excluído (Gugerli, 1999). Duas décadas depois cumpriram-se as previsões acerca do alcance da nova tecnologia. Na atualidade, "nada escapa ao olhar preciso da TC e da IRM, nem o conteúdo do estômago das múmias egípcias nem as estruturas musculares de um cadáver congelado no maciço de Ötztal, nem a anatomia de um criminoso executado, nem os processos fisiológicos no corpo de um atleta no treinamento para a olimpíada" (Gugerli, 1999).

As imagens de raios $X$, como vimos, não eram no início reconhecíveis de modo imediato. Imagens experts caracterizam-se precisamente por requerir expertise na interpretação, apesar de sua aparente legibilidade imediata para qualquer leigo. É necessário aprender a decodificá-las, o que exige um processo de aculturação. A "semelhança não diz respeito à relação entre a imagem e o seu objeto", nos lembra Umberto Eco, mas "àquela entre a imagem e um mundo previamente culturalizado" (citado em Dumit, 2004, p. 117). A existência de um vínculo entre a imagem e o contexto sociocultural no qual é produzida e atinge uma inteligibilidade é omitida freqüentemente no caso das técnicas de imageamento, dos raios X aos PET. Elas estendem ao século XXI a "retórica da auto-evidência" (Borck, 2001), presente desde a aparição da objetividade mecânica no século XIX (Daston \& Galison, 1992). Essas imagens constituem evidências sociotécnicas, isto é, sua função é produzir uma aparência de naturalidade e imediação que não deixa margem de dúvida, mas que na realidade oculta ou desloca - muitas vezes na recepção entusiástica das novas tecnologias - os contextos e pressupostos socioculturais e econômicos, nos quais essa evidência e naturalidade descansam. As imagens visuais, especialmente as imagens experts, possuem efetividade e "persuasividade desmedida" (Dumit, 2004, p. 112) que mascaram suas condições de possibilidade socioculturais, e os processos de aculturação nos quais adquirem sua inteligibilidade. Essa tendência ao ocultamento do contexto sociocultural e econômico, já presente nos raios $X$, torna-se mais significativa com as novas tecnologias de imageamento. Assim, por exemplo, o departamento de marketing da EMI Company, que desenvolveu os scanners de TC, surpreendeuse sobretudo quando os radiologistas não se interessaram pela novidade, precisamente porque nunca tinham visto o cérebro, ao contrário dos neurocirurgiões, que podiam olhar para as imagens e reconhecer o cérebro e sua morfologia. Como observa Michel Phelps, um 
dos criadores do PET, "em qualquer momento no qual você olha para alguma coisa diferente do que já viu anteriormente, tem de aprender a definir com que se parece. E você tem de aprender o que as normas determinam, antes de poder dizer 'Isto é normal'" (em Dumit, 2004, p. 118). As primeiras imagens de TC eram um enigma tanto para médicos como para radiologistas e cirurgiões. Robert Ledle, inventor de um dos primeiros scanners de TC, admite que teve de publicar o seu próprio atlas para ensinar aos radiologistas como 'ver' as imagens produzidas por seu scanner (Kevles, 1998). No caso do PET, os diferentes pesquisadores têm diferentes concepções sobre a natureza dos dados acerca da mente e do cérebro, sem conseguirem chegar a um acordo. A invenção constante de novos tipos de scanner, de novas técnicas de análise e novas maneiras de vincular os dados ao cérebro e ao comportamento tornam os resultados incomparáveis entre os diferentes aparelhos e métodos de análise (Dumit, 2004).

Outra diferença fundamental entre as novas tecnologias de imageamento e os raios $\mathrm{X}$ reside no fato de que as novas imagens não são fotografias (tampouco o eram os raios $X$, mas guardavam certa semelhança com ela), como esclarece a empresa construtora de scanners Fonar:

uma IRM não é uma fotografia. É de fato um mapa computadorizado ou uma imagem de sinais de rádio emitidos pelo corpo humano ... Embora essa imagem se pareça com uma foto, não é uma foto. Realmente, nas mãos de um radiologista experiente, a informação que fornece é muito mais útil que o que seria revelado por uma fotografia ... Para um radiologista de IRM experiente, esses tons cinzentos revelam volumes. (Apud Gugerli, 1999)

Embora funcione com o mesmo tipo de radiação que a tecnologia de raios $\mathrm{X}$, a tomografia computadorizada (TC) não produz fotografias. Os scanners de TC transmitem raios $X$ através do corpo para uma série de detetores, os quais enviam os sinais a um computador para seu processamento. O programa de computador transforma os sinais em pixels no monitor, criando uma imagem tridimensional do corpo. O computador pode realçar, colorir, aumentar ou diminuir a imagem. Ele permite certa liberdade no processamento dos dados para produzir imagens. No caso da IRM, as imagens são reconstruídas a partir de projeções de dados e podem ser manipuladas de diversas maneiras. A natureza dos sinais difere em TC e IRM, mas o problema que representa reconstruir uma imagem tridimensional a partir de um conjunto de dados provenientes do interior do corpo permanece o mesmo (Kevles, 1998; Blume, 1992; Wolbarst, 1999; Porter, 1999). Frente à TC e às IRM, consideradas técnicas de transmissão, a Tomografia por Emissão de Pósitrons PET, isto é, uma técnica de emissão que se refere ao lugar de origem 


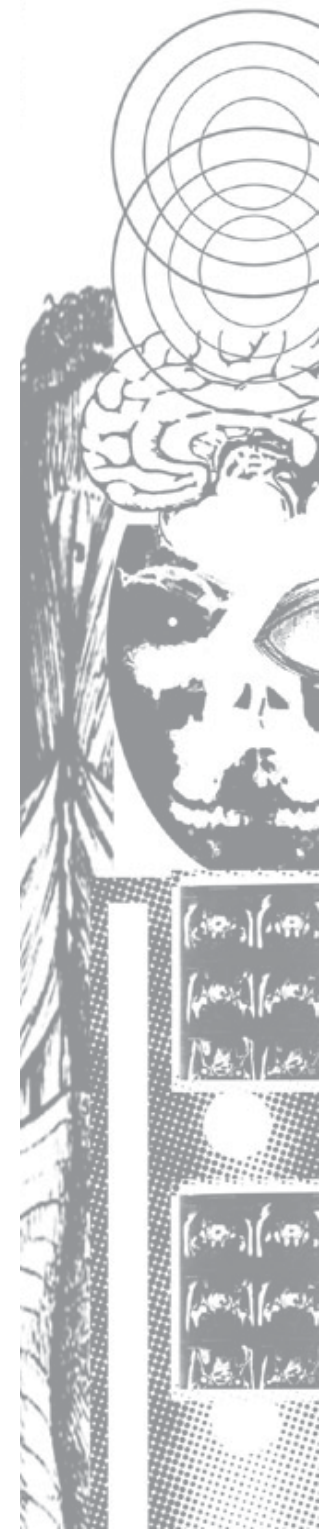

dos sinais no corpo, funciona injetando moléculas radiativas no corpo e depois rastreando sua posição no interior dele desde fora. Sua função não é tampouco, como a da TC e das IRM, produzir imagens de estruturas anatômicas determinadas, mas rastrear funções metabólicas. PET exige uma maior habilidade tanto para produzir como para interpretar as imagens, em comparação com as duas tecnologias anteriores. Não se lê uma imagem de PET como uma imagem radiológica. A última remete a uma morfologia, ao passo que a primeira representa uma função. No PET, os dados têm uma natureza fisiológica, funcional. As regiões do cérebro que mostram uma diferença na absorção das moléculas radiativas na imagem de PET não correspondem às regiões anatômicas do cérebro. O neurologista John Mazziota insiste nessa diferença: “uma premissa básica que deve ser descartada é a de que a anatomia estrutural e a funcional são equivalentes" (citado por Dumit, 2004, p. 196). Ou seja, a interpretação dessas imagens exige maior cuidado. Essa questão torna-se mais relevante quando pensamos no uso de cores nas imagens de PET, que representam um acréscimo necessário de significado suplementar com o objetivo de tornar a atividade visível para os seus observadores. Os defensores do uso de cores alegam que por não existir luz no inteiror do corpo não há uma cor ou iluminação real que possa ser reproduzida, e que o uso da cor ajuda a delimitar os diferentes tipos de tecido. Já os oponentes declinam sua utilização afirmando que a cor enfatiza as diferenças entre os tecidos e é usada apenas com fins publicitários e visando atrair investidores. Outra crítica comum é que as cores transformam diferenças quantitativas em variáveis categóricas (Kevles, 1998; Beaulieu, 2002). “A arbitrariedade das cores", escreve o antropólogo Joseph Dumit (2004, p. 93), "fortalece a sensação de que essas regiões são internamente coerentes, separadas de seus vizinhos, e, portanto, capazes de representar adequadamente o 'funcionamento da tarefa' em questão". Michel Ter-Pogossian, conhecido como 'o pai do PET', admite a arbitrariedade no uso das cores, pois elas podem "significar qualquer coisa que você queira que signifiquem" (citado em Dumit, 2004, p. 94). Um bom exemplo da multiplicidade de significações dada pelo uso das cores é o conjunto de 40 imagens de PET produzido pelo Departamento de Medicina Nuclear da State University of New York, no qual se repete a mesma imagem de um voluntário considerado normal e saudável, exibida em diferentes escalas cromáticas.

Considerando o seu apelo visual intuitivo, seu caráter imediato e familiar e sua suposta objetividade e neutralidade, e precisamente por possuir essas características, as novas imagens produzidas por PET e outras tecnologias recentes devem ser vistas com cautela. Além de abrir novos campos de estudo e investigação, colocam novos riscos que exigem uma maior responsabilidade dos pesquisadores. Robert 
Crease adverte acerca da ilusão de transparência, pois aparentemente estamos diante de "uma percepção de clareza cristalina do que 'realmente' está acontecendo no interior do corpo" (Crease, 1993, p. 554). Ver uma imagem como transparente ignora que as dimensões são feitas em termos de sua produção quantitativa e não apenas dos fenômenos que representam, e conclui,

porém, apesar de seus atrativos, ou talvez por causa deles, as imagens criam perigos intimamente emaranhados com os benefícios que as tecnologias de imageamento concedem. Um de tais benefícios é a ilusão de familiaridade. Ao contrário de uma tabela, mapa ou diagrama, uma imagem amiúde parece ser 'transparente', nos dando o objeto representado diretamente em vez de pela mediação de instrumentos falíveis que incorporam um determinado tipo de informação e excluem outro - talvez igualmente importante - tipo de dados. Uma imagem pode nos iludir e levar a pensar que podemos conhecer um objeto de uma maneira que um gráfico nunca poderia igualar. (idem, p. 561; cf. Beaulieu, 2002)

Numa 'era pós-fotográfica' na qual todo tipo de recursos tais como retoques, pinceladas eletrônicas, modificações de cores e tamanhos são disponíveis na maioria dos computadores que usamos cotidianamente, a produção de compromissos visuais e evidências apenas pode ser garantida mediante seguranças institucionais tais como standards de formação de profissionais, vistorias rotineiras dos procedimentos e autocontrole dos profissionais, entre outras (Gugerli, 1999). Além disso, não devemos esquecer que as técnicas eletrônicas de produção de imagens já são per se manipuladoras, isto é, elas apagam os limites entre a cópia e o original, pois unicamente a representação manipulada tecnicamente pode reclamar 'originalidade' (Borck, 2001, p. 391).

\section{Imagens do cérebro nos tribunais}

Analogamente ao destino dos raios $X$, as novas imagens têm encontrado seu caminho nos tribunais. Em 1982 foram usadas pela primeira vez imagens de CT para atestar a insanidade de alguém John Hinckley, que havia atirado um ano antes contra o presidente dos Estados Unidos, Ronald Reagan, e cinco outras pessoas. Durante o julgamento, o psiquiatra David Bear mostrou imagens de CT do cérebro de Hinckley que, segundo ele, demostravam a presença da esquizofrenia, afirmando que "existem evidências esmagadoras de que a fisiologia do cérebro esteja relacionada com as emoções de um indíviduo e de que a aparência anormal do cérebro esteja relacionada com a esquizofrenia" (citado por Kevles, 1998, p. 170). Aparentemente os sulcos do cérebro de Hinckley eram rasos, 
o que apontava para a existência da doença, pois um terço dos esquizofrênicos autopsiados apresentavam essa peculiaridade. Ojuiz aceitou a evidência e o júri admitiu o significado das imagens, declarando Hinckley inocente por insanidade. A partir daí o uso de TC em alegações de insanidade tornou-se comum. As IRM (Tomografias de Ressonância Magnética), por sua parte, são utilizadas nos tribunais em casos do que os pediatras denominaram 'trauma parental induzido' (Parental Induced Trauma), isto é, bebês que são sacudidos, provocando sérios danos cerebrais ou até a morte. O uso de imagens PET como evidências é ainda mais complicado pois, diferentemente de imagens de TC ou IRM que mostram a estrutura do cérebro e são relativamente estáveis durante o tempo, as imagens de funções cerebrais produzidas com PET-scanners podem variar continuamente, dependendo da atividade do indivíduo, dificultando o isolamento de doenças mentais e a definição de danos neurológicos, por exemplo. Por esses motivos muitos pesquisadores se opõem a seu uso nos tribunais, o que não impede a sua proliferação.

No filme Rampage, de 1988, o advogado do personagem Charles Reese, acusado de cometer seis assassinatos e próximo de ser condenado pelo júri, exige um exame feito por um PET-scanner antes de passar a sentença. Segundo as palavras do especialista, "esta área amarelo-verde é compatível com a esquizofrenia. O que os senhores estão vendo é uma imagem realçada pelo computador da química do cérebro. E o que mostra é um retrato da loucura (picture of madness)" (citado em Dumit, 2000, p. 92; ver também Dumit, $1999,2004)$. O júri, convencido, envia Reese a um hospital mental, poupando-o da câmera de gás. Uma imagem vale mais que mil palavras. O júri aceitou o raciocínio de que o resultado anormal do exame de um cérebro denota um cérebro anormal em uma pessoa anormal, que não pode ser responsabilizada pelas suas ações. A propensão para a violência é explicada exclusivamente em termos de química cerebral, ignorando os condicionamentos sociais e ambientais. Mas até este momento não foi demonstrada nenhuma conexão necessária entre um cérebro anormal e a doença mental. Ainda não foram encontrados os marcadores biológicos da esquizofrenia ou da depressão, apesar de décadas de pesquisas. As imagens de CT e PET contribuíram notavelmente para a definição da doença mental como um defeito biológico. As novas tecnolo-gias de imageamento tornaram-se o 'santo graal' da psiquiatria biológica. A visualização do cérebro anormal ocupa o lugar do diagnóstico da mente anormal. Um artigo sobre PET escrito por um adepto da psiquiatria biológica começa desta maneira: “Nos anos 70, o movimento da antipsiquiatria quase que acaba conosco ... mas agora temos a prova" (citado por Dumit, 2004, p. 153). 
6 Veja, 4.08.2004. Disponível em: veja.abril.uol.com.br/ 040804/p_124.html.

\section{Visualização do cérebro e cultura popular}

As metáforas fundacionais das neurociências permeiam a cultura popular. Os jornais e as revistas de divulgação científica, a televisão e o cinema veiculam continuamente imagens que insistem na associação entre o cérebro e a mente, a mente no cérebro. Concordo com Dumit (2004) em que a mídia capitaliza precisamente a potente familiaridade e transparência das imagens. O risco é grande, os limites entre as imagens entendidas como representações de correlações ou de relações causais entre estados mentais e estruturas cerebrais são ultrapassados com freqüência, sendo interpretadas como registros objetivos de estados emocionais e mentais, como por exemplo, de insanidade. Quando uma cultura como a nossa equaliza o estatuto cerebral com o estatuto mental e com a própria personalidade, então as imagens tornam-se prejudiciais ao difundir visões reducionistas e objetivizadas da mente e do corpo humano, com conseqüências severas em diversas esferas socioculturais e clínicas.

Enquanto escrevo estas páginas vejo a capa da edição da revista Veja sobre "O novo mapa do cérebro", que me oferece uma ilustração preciosa do argumento que estou apresentando. A reportagem da capa, "O cérebro devassado", , é dedicada aos mais recentes avanços em neuroimageamento. As promessas da nova tecnologia são infinitas: "Como esses exames podem flagrar o cérebro em plena atividade, os pesquisadores estão conseguindo mapear praticamente tudo o que acontece dentro dele - como se processam as emoções, a cognição, o pensamento e o raciocínio e até mesmo como se originam algumas doenças". Além de aludir aos avanços no tratamento de depressões e esquizofrenia, o artigo menciona a nova onda de neuromarketing, na qual são utilizadas as imagens do cérebro para conhecer que áreas são ativadas quando os indivíduos são expostos a marcas, produtos e imagens de todo tipo, e até às falas de políticos. A partir das diferentes reações, são direcionadas as campanhas publicitárias ou de marketing político. Por exemplo, em uma pesquisa recente com voluntários democratas e republicanos, observou-se a reação cerebral diferente de cada pessoa segundo lhe fosse mostrada uma foto de George W. Bush ou de John Kerry: "Confrontadas com fotos de seus próprios candidatos, elas tiveram ativada uma parte do córtex pré-frontal associada a reações instintivas. Mas, quando a imagem era do candidato do outro partido, ativaram-se áreas mais voltadas para a racionalidade".

Entre as companhias que utilizaram no ano passado os serviços de neuromarketing da empresa de marketing americana BrightHouse de Atlanta, se encontram a Coca-Cola e a companhia aérea Delta Airlines, bem como dois fabricantes de carros, a Daimler Chrysler e a Ford européia. O resultado da pesquisa feita pela Coca-Cola 
7 Os detalhes do procedimento de apagar memórias no cérebro são explicados no site da empresa 'lacuna' na Internet. Disponível em:

www.lacunainc.com/ process.html. merece ser mencionado. Embora as imagens mostrassem uma "maior preferência cerebral" pelo sabor da Pepsi, a Coca-Cola estimulava mais as áreas do cérebro ligadas aos atos de vontade, o que traduzido comercialmente quer dizer que "seu logotipo é mais poderoso que o da Pepsi" e, portanto, vende mais.

No cinema americano, a identificação da mente com o cérebro tornou-se lugar comum, um fato objetivo sem nenhum tipo de questionamento. Três filmes recentes são um bom exemplo disso. Nos três, o papel das imagens produzidas pelas tecnologias de neuroimageamento é central. Em O Pagamento (Paycheck), de 2003, dirigida por John Woo, baseado em um conto de Phillip K. Dick, o protagonista, Michael Jennings, interpretado por Ben Affleck, é um engenheiro de computação brilhante, constantemente contratado por grandes empresas para trabalhar em projetos secretos. Sempre que conclui a execução de um desses projetos, Jennings passa por um processo no qual parte de sua memória de curto prazo é apagada, para evitar que informações secretas vazem. O pagamento é proporcional à quantidade de bites de memória apagada do cérebro do protagonista. No segundo filme, Efeito borboleta (The Butterfly Effect), de 2004, dirigido por Eric Bress e J. Mackye Gruber, Evan (Ashton Kutcher) é um jovem que luta para esquecer fatos de sua infância. Para tanto ele decide realizar uma regressão pela qual volta também fisicamente ao seu corpo de criança, tendo condições de alterar seu próprio passado e gerar conseqüências em seu futuro. Após cada retorno ao passado, as imagens cerebrais mostram uma dilatação ou inchação na zona do cérebro onde a memória é armazenada, levando a sangramentos de nariz cada vez mais sérios, já que cada vez que o protagonista regressa ao passado, novas memórias são acrescentadas. Por fim, no mais instigante e inteligente dos três filmes, Brilho eterno de uma mente sem lembranças (Eternal sunshine of the spotless mind), de 2004, dirigido por Michel Gondry com roteiro de Charlie Kaufman, Joel (Jim Carrey) e Clementine (Kate Winslet) formavam um casal durante anos. Desiludida com o fracasso do relacionamento, Clementine decide esquecer Joel para sempre e, para tanto, aceita submeter-se a um tratamento experimental, que retira de sua memória os momentos vividos em conjunto. Quando Joel toma conhecimento do acontecido, submete-se ao mesmo procedimento de apagar as memórias, oferecido pela empresa 'lacuna'. ${ }^{7}$ Porém ele acaba desistindo de tentar esquecê-la, e, fugindo dos apagadores de memórias, começa a encaixar Clementine em momentos de sua memória nos quais ela não participa. No filme, tudo acontece no cérebro dos personagens Clementine quer 'apagar Joel do seu cérebro' e Joel, Clementine. À fuga de Joel e Clementine nas memórias da infância de Joel corresponde a perseguição desenfreada dessa memória pelos técnicos de 'lacuna' no mapa cerebral do protagonista. 
${ }^{8}$ No final do século XIX, o filósofo francês Henri Bergson fez uma crítica contundente à concepção de que o cérebro armazena memórias, no seu livro Matéria e memória, publicado em 1896.
Enfim, estender-me sobre esse assunto fascinante ultrapassaria os limites e objetivos deste artigo. Em poucas palavras, os três filmes mencionados, assim como muitas matérias veiculadas em revistas de divulgação, compartilham uma série de premissas que não são explicitadas, em parte porque se tornaram lugar comum na cultura popular. Esses pressupostos estavam presentes nos projetos frenológicos e localizacionistas do século XIX, nos quais galos ou protuberâncias no crânio eram associados com diferentes faculdades mentais e funções patológicas eram vinculadas às diferentes regiões cerebrais. Muitos neurocientistas que trabalham com neuroimageamento não denigrem a frenologia; para eles, o movimento frenológico formulou as questões corretas com a tecnologia errada, donde o rótulo de neofrenologia e neolocalizacionismo (Uttal, 2001; Dumit, 2004; Beaulieu, 2002; Stafford, 1996). Entre as principais premissas sobre o cérebro presentes na cultura popular - e não apenas nela - que não são explicitadas, estão: que o cérebro armazena memórias, ${ }^{8}$ que a mente é, no fundo, o cérebro, e que o ser humano é constituído essencialmente pelo cérebro, isto é, tratase de uma nova figura antropológica que podemos denominar 'sujeito cerebral' (Vidal, 2002, 2005a, 2005b).

Esta última premissa é muito importante para a temática deste artigo, pois, na noção de pessoa como basicamente o cérebro está implicada a redução do corpo ao cérebro. O crescente processo de hiperespecialização e tecnificação pelo qual passa a biomedicina contemporânea leva a isolar partes ou órgãos do corpo de sua totalidade somática. É a única maneira de atingir a eficácia diagnóstica e terapêutica desejada. Porém, no caso da neurociência mainstream, a tendência a superestimar o cerebral na descrição da pessoa e do corpo humano é incentivada pela idéia da 'cabeça transparente' inspirada pelas tecnologias de imageamento. As imagens produzidas com os scanners de TC, IRM ou PET fornecem a estranha ilusão de corpos fragmentados, partes isoladas da anatomia, as quais, deslocadas da totalidade corporal ou da coerência sensorial, ganham uma autonomia enganosa. São corpos sem substância, roubados de sua opacidade e descontextualizados. Nesse processo, o cérebro e o feto são os ícones favoritos das novas imagens. No caso do feto, Chazan (2003) tem ressaltado a "construção do feto como pessoa" pelas novas tecnologias de imageamento. A computação gráfica aplicada à ultra-sonografia constrói imagens gráficas tridimensionais do feto anteriores ao aparecimento de qualquer tipo de sensação materna. Como no filme de Stanley Kubrick, 2001 - Uma odisséia no espaço, o feto aparece nas imagens isolado e descontextualizado de seu ambiente, no caso, intra-uterino. A mãe não existe mais, o feto é construído como uma pessoa independente e autônoma. Essas imagens são um prato cheio para as campanhas antiabortistas, as quais precisamente colocam a vida do feto acima 
9 A empresa Alcor oferece os serviços de congelamento do corpo inteiro por 120 mil dólares, ou apenas o cérebro, uma solução que sai bem mais em conta, custando 50 mil dólares, mais taxa de transporte de $20 \mathrm{mil}$ dólares.Disponível em:www.terra.com.br/ istoe/1712/ciencia/ 1712 _vida_apos_ a_morte.htm. O fato de a segunda opção ser oferecida pela empresa e as pessoas optarem por ela envolve a crença de que o cérebro é a parte do corpo necessária para sustentar a identidade pessoal.

${ }^{10}$ Numa matéria da BBC, de 27.10.2003, aparece a notícia de que o artista

americano Jonathon Keats, de 32 anos, está vendendo os royalties de seu cérebro. A idéia de Keats é que o seu cérebro continue funcionando mesmo depois da sua morte: "Quando ele morrer, os seis bilhões de neurônios do seu cérebro serão transferidos à Jonathon Keats Holding Co. Quem tiver comprado a 'opção' (o direito de compra futura) poderá comprar a cota de um milhão de neurônios por 10 mil dólares. Em princípio, seriam reunidos 60 milhões de dólares, e parte do dinheiro seria usada para cobrir os custos para manter o cérebro funcionando".

Disponível em: www.0bbc.co.uk/ portuguese/ciencia/ story/2003/10/ printable/

031027_cerebrocg.chtml da liberdade de escolha da mãe. Ao mesmo tempo, a ilusão de autonomia e independência está de acordo com nossa cultura individualista, na qual a dependência é vista como uma falha e uma fraqueza. O cérebro também aparece recortado de seu contexto anatômico nas imagens obtidas mediante as tecnologias de neuroimageamento. Análoga à construção social do feto como pessoa, aparece a produção do cérebro como pessoa, o sujeito cerebral descarnado, sem contexto corporal. A dupla cisão, a do cérebro em relação ao contexto corporal e a do corpo em relação ao ambiente, é pressuposta tanto nos debates sobre morte cerebral (Lock, 2002), criogenia isto é, congelamento do cérebro após a morte para ser 'ressuscitado' quando os avanços biotecnológicos o permitam $-{ }^{9}{ }^{9}$ venda do cérebro, ${ }^{10}$ quanto nas explicações da psiquiatria biológica da depressão e da esquizofrenia exclusivamente em termos da química cerebral.

\section{Conclusão}

Só posso concordar com Stafford (1996, p. 133), quando afirma que as reconstruções do corpo e do cérebro feitas pelas novas imagens são "reconstruções aparentemente sem vida interna, privadas de evidências reconhecíveis de angústia ou dor, as quais ou deslocam a mente de suas circunstâncias materiais ou tornam o corpo imaterial". A imagem do corpo fornecido pelas novas tecnologias é a de um corpo fragmentado, objetivado e desmaterializado, recortado do ambiente. É o corpo-objeto da tradição anatomofisiológica, sem opacidade nem subjetividade. O nosso corpo é reconstruído a partir do modelo do corpo fornecido pela medicina e pela mídia como um corpo objetivado e fragmentado, privado de sua dimensão subjetiva, o corpo como algo que temos e não algo que somos. Podemos usar a expressão "autoconstituição objetiva" (objective selffashioning) (Dumit, 2004) para nos referirmos ao processo de formação de um self objetivo, isto é, uma categoria de pessoa desenvolvida mediante conhecimento expert. É um processo duplo: por um lado, a ciência produz fatos que definem objetivamente quem somos; por outro, os indivíduos formam seus próprios modelos de self a partir dos fatos científicos popularizados pela mídia. As tecnologias de imageamento são uma nova e poderosa fonte de recursos para a formação de um self e um corpo objetivados. Elas estão contribuindo para a desincorporação da subjetividade e para a virtualização e objetivação da corporeidade, tornando obsoleto o corpo. A apreensão objetiva e descarnada do corpo é oposta a nossa experiência subjetiva, encarnada do corpo unificado, o corpo como localização física desde a qual falamos, agimos e conhecemos. Esse corpo, o corpo que somos e temos, não é apenas um objeto de controle, vigilância e escrutínio, nem uma construção discursiva, midiática ou espetacular, mas o sujeito da experiência e da ação. 


\section{REFERÊNCIAS BIBLIOGRÁFICAS}

Beaulieu, Anne 2002

Bergson, Henri 1999

Blume, Stuart S. 1992

Borck, Cornelius 2001

Cartwright, Lisa 1997

Chazan, Lilian Krakowski 2003

Crease, Robert 1993

Danius, Sara 2000

Daston, Lorraine;

Galison, Peter

1992

Dolby, T.; Alker, G. 1997

Dumit, Joseph 2004

Dumit, Joseph 2000

Dumit, Joseph 1999

Gugerli, David 1999

Horgan, John 2003

Kemp, Martin 1998

Kevles, Bettyann Holtzmann 1998

Lippit, Akira Mizuta 1996

Lock, Margaret 2002
Images are not the (only) truth: brain mapping, visual knowledge, and iconoclasm. Science, technology E Human Values, v. 27, n. 1, p. 53-86.

Matéria e memória.

São Paulo: Martins Fontes.

Insight and industry. On the dynamics of technological change in medicine.

Cambridge (Mass.) and London: The MIT Press.

Die unhintergehbarkeit des Bildschirms. Beobachtungen zur Rolle von Bildtechniken in den präsentierten Wissenschaften'. In: Heinz, B.; Huber, J. (org.) Mit dem Auge denken. Strategien der Sichtbarmachung in wissenschaftlichen und virtuellen Welten. Zürich: Voldemeer. p. 383-94.

Screening the Body. Tracing Medicine's Visual Culture.

Minneapolis: University of Minnesota Press.

O corpo transparente e o panóptico expandido: considerações sobre as tecnologias de imagem nas reconfigurações da pessoa contemporânea. Physis: Revista de Saúde Coletiva, v. 13, n. 1, p. 193-214.

Biomedicine in the Age of Imaging.

Science, v. 261, n. 5121, p. 554-61.

Novel visions and the crisis of culture: visual technology, modernism, and death in The magic mountain. Boundary 2, v. 27, n. 2, p. 177-211.

The image of objectivity.

Representations, v. 40, p. 81-128.

Origins and development of medical imaging.

Carbondale and Edwardsville: Southern Illinois University Press.

Picturing personhood. Brain scans and biomedical identity. Princeton: Princeton University Press.

A digital image of the category of person. PET Scanning and Objective Self-Fashioning. In: Downey, G. L.; Dumit, J. (org.) Cyborgs and citadels. Anthropological interventions in emerging sciences and technologies. Santa Fe (NMex): School of American Research Press, p. 83-102.

Objective brains, prejudicial images.

Science in Context, v. 12, n. 1, p. 173-201.

Soziotechnische Evidenzen. Der 'pictorial turn' als Chance für die Geschichtswissenschaft. Traverse (Wissenschaft, die Bilder schafft), v. 3, p. 131-59.

Rational mysticism. Dispatches form the border between science and spirituality. Boston and New York: Houghton Mifflin.

A perfect and faithful record: mind and body in medical photography before 1900. In: Thomas, A. (org.) Beauty of another order. Photography in science. New Haven and London: Yale University Press. p. 120-49.

Naked to the bone. Medical imaging in the twentieth century.

Reading (Mass.): Helix Books.

Phenomenologies of the Surface: Radiation-Body-Image.

Qui parle. Literature, philosophy, visual arts, history, v. 9, n. 2, p. 31-50.

Twice dead. Organ transplants and the reinvention of death.

Berkeley and Los Angeles: University of California Press. 
Mann, Thomas

2000

Porter, Roy

1999

Reiser, Stanley Joel

1990

Segal, Alain

1979

Stafford, Barbara Maria 1996

Uttal, William R. 2001

Vidal, Fernando 2005a

Vidal, Fernando $2005 b$

Vidal, Fernando 2002

Vogel, Klaus

1999

Wolbarst, Anthony Brinton

1999
A montanha mágica.

Rio de Janeiro: Nova Fronteira.

The greatest benefit to humankind: a medical history of humanity. New York: W. W. Norton.

Medicine and the reign of technology.

Cambridge: Cambridge University Press.

Les progrès de l'exploration visuelle des organes aux XVIIe et XVIIIe siècles. Histoire des sciences médicales, v. 13, n. 1, p. 395-406.

Good looking. Essays on the virtue of images. Cambridge (Mass.): The MIT Press.

The new phrenology. The limits of localizing cognitive processes in the brain. Cambridge (Mass.) and London: The MIT Press.

Sujet cérébral. In: Andrieu, B. (org.) Dictionnaire du corps. Paris: CNRS. (no prelo)

Brainhood. In: Fischer, K. et al. (org.) Mind, brain, and education (based on a conference held at the Pontifical Academy of Sciences, Rome). New York: Cambridge University Press. (no prelo)

Brains, bodies, selves, and science. Anthropologies of identity and the resurrection of the body. Critical Inquiry, v. 28, n. 4, p. 930-74.

The transparent man - some comments on the history of a symbol. In: Bud, R. et al. (org.) Manifesting medicine. Bodies and machines. Amsterdam: Harwood Academic Publishers. p. 31-61.

Looking within. How X-ray, CT, MRI, ultrasound and other medical images are created and how they help physicians save lives. Berkeley and Los Angeles: University of California Press. 